\title{
Prevalence and Correlates of Mycoplasma genitalium Infections among Patients Attending a Sexually Transmitted Infection Clinic in Guangdong, China a Cross-sectional Study
}

\section{Xiaohui Zhang}

Guangdong Provincial Dermatology Hospital

PZ Zhao

Guangdong Provincial Dermatology Hospital

WJ Ke

Guangdong Provincial Dermatology Hospital

\section{LY Wang}

Guangdong Provincial Dermatology Hospital

\section{Lai Sze Tso}

Massachusetts Institute of Technology

\section{ZY Chen}

Guangdong Provincial Dermatology Hospital

YY Liao

Guangdong Provincial Dermatology Hospital

CM Liang

Guangdong Provincial Dermatology Hospital

HR Chen

Guangdong Provincial Dermatology Hospital

$X Q$ Ren

Guangdong Provincial Dermatology Hospital

JM Huang

Guangdong Provincial Dermatology Hospital

\section{JJ Ong}

Monash University

\section{F Yang}

University of North Carolina at Chapel Hill

Ligang Yang ( $\sim$ yanglg3@hotmail.com )

https://orcid.org/0000-0002-6775-8970 
Research article

Keywords: Prevalence, Mycoplasma genitalium, risk factor

Posted Date: February 11th, 2020

DOl: https://doi.org/10.21203/rs.2.23186/v1

License: (c) (i) This work is licensed under a Creative Commons Attribution 4.0 International License.

Read Full License

Version of Record: A version of this preprint was published at BMC Infectious Diseases on July 5th, 2021. See the published version at https://doi.org/10.1186/s12879-021-06349-4. 


\section{Abstract}

Background Mycoplasma genitalium (MG) is known to cause urogenital tract infections and is associated with reproductive morbidity. Although MG has been reported across many regions and population groups, it is not yet routinely tested for in China. Our study contributes to current research by reporting the prevalence and correlates of MG for patients attending a sexually transmitted infection (STI) clinic in Guangdong from Jan 2017-May 2018.

Methods Urethral (489 men) and endo-cervical (189 women) samples, blood samples, and patient histories (via questionnaires) were collected. Doctors clinically diagnosed anogenital warts (GW) during the examination ( $n=678)$. Presence of $M G$ was tested using an in-house polymerase chain reaction. We also tested all participants for herpes simplex virus-2 (HSV-2), Neisseria gonorrhoeae (NG), Chlamydia trachomatis (CT), syphilis and HIV. Univariate and multivariable logistic regressions were used to evaluate factors associated with MG.

Results MG was detected among 7.2\% ( $n=49)$ of patients ( $7.4 \%$ men, $6.9 \%$ women). Of 629 heterosexual patients, the MG was detected in 7.5\% (47/629), and of 49 MSM, MG was detected in $4.1 \%(2 / 49)$. Among MG-infected patients, $10.2 \%$ were co-infected with CT, $6.1 \%$ with NG, $8.2 \%$ with HSV-2, $4.1 \%$ with syphilis and $22.4 \%$ with GW. Among 152 symptomatic patients, the prevalence of MG was $12.5 \%(n=19$, of whom 17 were men). Being symptomatic was statistically significant for MG infection $[\mathrm{OR}=2.2(1.3 \sim 3.8)]$.

Conclusion MG is a relatively common infection among individuals attending an STI clinic in Guangdong province. To make MG testing available and routinely screen symptomatic patients with urinary and /or cervical discharge in STI clinics in China is essential.

\section{Introduction}

Mycoplasma genitalium (MG), first isolated from urethral specimens of two men with non-gonococcal urethritis in 1981[1], is the smallest free-living and self-replicating sexually transmitted pathogen[2]. Since this initial discovery, MG is now accepted as a cause of urogenital tract infections and is associated with a variety of other reproductive morbidity. According to studies from as early as 1993, MG was identified as a cause of acute and persistent non-gonococcal urethritis (NGU)[3], prostatitis[4], balanoposthitis[5], and proctitis[6-8] among male patients. For females, MG has been associated with urethritis and cervicitis[9][Falk, 2005 \#136], pelvic inflammatory disease (PID)[10], human papillomavirus (HPV)[11], and adverse pregnancy outcomes[12]. For both men and women, MG has been associated with infertility $[12,13]$ and transmission of the human immunodeficiency virus (HIV)[14]. Through intracellular localization and antigenic variation, MG could result in treatment-resistant chronic infection[15, 16].

In recent decades, a number of epidemiological studies investigated genital mycoplasma infection and its associated adverse sequelae. Molecular assays are the major diagnostic technique for MG detection. However, there is no standard screening protocol for MG in China. Nor is there any international 
guidelines that may be adapted for use in China[17]. Hence, despite the evidence of adverse effects and the detrimental impact of MG, most facilities in China have not and do not routinely test for MG.

Furthermore, many sexually transmitted infection (STI) clinics in China lack the required diagnostics for MG. Therefore, the prevalence data of MG in high-risk populations are limited in many parts of China.

With the available studies of MG in men living in China, the prevalence was $3.4 \%$ from the first void urine (FVU) and $5.4 \%$ in the rectal samples of the men sex with men (MSM) in Shenzhen[18], but $15.3 \%$ in the rectal samples of MSM in Shenyang[19]. Among men living with HIV in Jiangsu province, the prevalence ranged from $20.1 \%$ to $29.2 \%$ in the FVU[20-23]. The prevalence for MG was $10.2 \%$ in symptomatic patients with non-gonococcal urethritis (NGU) and $13.9 \%$ in patients with asymptomatic NGU in Hongkong[24, 25] and $28.1 \%$ in the men with STD-related complaints in Guangxi[26]. In women, the MG prevalence data is even more limited. One study reported $13.2 \%$ prevalence in female sex workers living in Jiangsu[27]. Furthermore, the national prevalence data of MG among the routine STI patients is lacking, including from the biggest city, Guangzhou. So we conducted a cross-sectional study among the patients presenting to a major urban STI clinic in Guangzhou, Guangdong Province, to assess the prevalence and correlates for MG infection.

\section{Methods}

Study design

From January 2017 until May 2018, all patients attending the STI Clinic in the Dermatology Hospital of Southern Medical University were tested for MG. Included in the study were symptomatic or asymptomatic adults seeking STI screening. Patients aged less than 18-years or reporting any systemic antibiotic treatment in the previous 30 days were excluded. After providing informed consent, participants completed a questionnaire in a private room at the clinic which included questions on their sociodemographic characteristics, sexual behaviors and clinical data.

Pathogen Detection

Urethral swab specimens and FVU, at least 2 hours after the last urination, were collected from all men, including those who reported no symptoms. The urethral swab specimens were used for urethral leucocytes count and MG detection. The urine specimens were tested for Neisseria gonorrhoeae (NG) and Chlamydia trachomatis (CT). For women, endo-cervical swab specimens were collected for MG/NG/CT nuclear acid amplification test and leucocyte count using microscopy. Blood sera were tested for HIV, Treponema pallidum (TP) and Herpes simplex virus 2 (HSV-2) antibodies.

The amplification assay detecting MG was performed by series: DNA was extracted using the commercial kit according to the manufacturer's instructions (Daan, Guangzhou, China). An in-house quantitative 5' nuclease assay (TaqMan PCR) was developed and validated according to the method described by Jensen et al.[28]. The assay detected a fragment of the MgPa adhesin gene by the use of a TaqMan MGB (minor groove binder) probe and included an internal processing control to detect PCR inhibition. NG and CT were tested using the Roche's Cobas 4800 CT/NG test (Roche Diagnostics, Mannheim, Germany). 
Serum was tested for HIV using two antibody tests - a rapid HIV antibody test (Wantai, Beijing, China) and a second antibody test (Abon Biopharm, Hangzhou, China). If both were positive, another blood sample was collected for Western blot confirmation (MP Biomedical, Singapore). Serum was tested for syphilis using a toluidine red unheated serum test (TRUST, Rongsheng Bio-technology Limited Corporation, Shanghai, China) and Treponema pallidum particle agglutination test (TPPA, Fujirebio Inc, Japan). Serum was tested for herpes simplex virus 2 using the enzyme-linked immunosorbent assay (ELISA) method (Trinity Biotech, Guangzhou, China). Samples were stored at $-20^{\circ} \mathrm{C}$ before test.

\section{Measures}

Patients were considered to be symptomatic if they self-reported or presented with dysuria and/or urethral pruritus, had clinical manifestations of balanoposthitis or urethral discharge (for males) or abnormal vaginal discharge and/or vaginal bleeding after sexual contact; yellowish mucopurulent discharge at the cervical os and/or contact bleeding of the cervix (for females).

Patients with positive TRUST and TPPA tests were considered to have an active syphilis infection; unless there was a documented history of previously treated syphilis. Men with positive HIV screening and confirmatory tests were considered to have HIV infection. Anogenital warts (GW) and anogenital herpes (GH) were diagnosed according to the diagnostic criteria for China's notifiable diseases reporting system (Version 2008). These diagnoses were mainly based on exposure history and consistent clinical findings.

\section{Ethics Approval}

The study was approved by the Ethics Committee of Dermatology Hospital of Southern Medical University (approval no. GDDHLS - 201502, 31/03/2015). Oral informed consent was obtained from all study participants prior to inclusion in the study.

Statistical analysis

All data were entered into EpiData 3.0 via double entry for statistical analysis. Descriptive analyses were conducted on patients' demographics, prevalence of MG and other STIs. The Chi-square test was used to compare categorical variables between $M G$ positive and negative participants. $P$ value $<0.05$ was considered statistical significance. Univariate and multivariable logistic regressions were used to evaluate factors associated with MG. All data were analyzed using SAS 9.4 (SAS int. Cary, NC, USA).

\section{Results}

Characteristics of the study participants

During the 17-month study period, 727 individuals were recruited using convenience sampling. However, 49 individuals were excluded due to incomplete data. So we analyzed data from 678 patients: 489 (72\%) men and 189 (28\%) women. These individuals attended our STI outpatient department with symptoms or had an asymptomatic STI screening due to high-risk sexual behaviors or being a contact of infection. The 
mean age of the study population was $34.02 \pm 13.39$ years ( $33.70 \pm 9.23$ years for men and $34.83 \pm$ 20.35 years for women). Of the 489 men, $41(6 \%)$ identified themselves as gay and $8(1 \%)$ as bisexual. None of the women identified themselves as lesbians or bisexual. Half of the participants were married and $66 \%$ had completed a high education. Most $(77 \%)$ had been living in Guangzhou for more than six months.

Among the 678 participants, 152 (22.4\%) were symptomatic (19.6\% (133/678) were males and $2.8 \%$ $(19 / 678)$ were females). Other patient characteristics and results of MG tests are shown in Table 1. 
Table 1

Demographic and behavioral characteristics of study participants attending the hospital STI clinic in Guangzhou, 2017-2018 ( $\mathrm{n}=678)$

\begin{tabular}{|c|c|c|c|}
\hline Characteristic & Total & $\begin{array}{l}\text { MG positive } n(\%) \text { (percentage of individuals with } \\
\text { characteristic) }\end{array}$ & $\begin{array}{l}P \\
\text { value }\end{array}$ \\
\hline Gender & & & 0.827 \\
\hline Male & 489 & $36(7.36)$ & \\
\hline Female & 189 & $13(6.88)$ & \\
\hline Age (years) & & & 0.158 \\
\hline $0-25$ & 136 & $15(11.03)$ & \\
\hline $26-45$ & 474 & $30(6.33)$ & \\
\hline$>45$ & 68 & $4(5.88)$ & \\
\hline Marital status & & & 0.264 \\
\hline Single & 309 & $23(7.44)$ & \\
\hline Currently married & 342 & $22(6.43)$ & \\
\hline Others & 27 & $4(14.81)$ & \\
\hline Local living time & & & 0.258 \\
\hline Less than 6 months & 155 & $8(5.16)$ & \\
\hline More than 6 months & 523 & $41(7.83)$ & \\
\hline Education & & & 0.329 \\
\hline Middle school or less & 119 & $5(4.20)$ & \\
\hline Senior school & 109 & $8(7.34)$ & \\
\hline $\begin{array}{l}\text { Secondary school or junior } \\
\text { collage }\end{array}$ & 203 & $13(6.40)$ & \\
\hline Bachelor or more & 247 & $23(9.31)$ & \\
\hline Sexual orientation & & & 0.377 \\
\hline Heterosexual & 629 & $47(7.47)$ & \\
\hline MSM & 49 & $2(4.08)$ & \\
\hline Condom use in ${ }^{*} \mathrm{P} 6 \mathrm{~m}$ & & & 0.035 \\
\hline
\end{tabular}




\begin{tabular}{|c|c|c|c|}
\hline Characteristic & Total & $\begin{array}{l}\text { MG positive } n(\%) \text { (percentage of individuals with } \\
\text { characteristic) }\end{array}$ & $\begin{array}{l}P \\
\text { value }\end{array}$ \\
\hline Always & 76 & $1(1.32)$ & \\
\hline Not all the time & 602 & $48(7.97)$ & \\
\hline Sexual partner in ${ }^{*} \mathrm{P} 6 \mathrm{~m}$ & & & 0.474 \\
\hline $0 \sim 1$ & 368 & $23(6.25)$ & \\
\hline $2 \sim 3$ & 262 & $21(8.02)$ & \\
\hline$>3$ & 48 & $5(10.42)$ & \\
\hline${ }^{*}$ Symptomatic & & & 0.004 \\
\hline No & 526 & $30(5.70)$ & \\
\hline Yes & 152 & $19(12.50)$ & \\
\hline
\end{tabular}

MG prevalence and clinical characteristics of the infected patients

MG was detected in $7.2 \%$ (49/678) of all patients included in the study, corresponding to $7.4 \%(36 / 489)$ among men, and to $6.9 \%(13 / 189)$ among women. The positive results of $M G$ among all the symptomatic and asymptomatic patients was $12.5 \%$ and $13.9 \%$, respectively.

In patients with MG, only $38.8 \%$ (19/49) were symptomatic of whom $18.4 \%$ (9/49) were co-infected with CT and/or NG. Besides the patients who were MG co-infected with CT and/or NG, 43.3\% (13/30) MG infected men had self-reported symptoms, while this is only $10 \%(1 / 10)$ for women. During the physical examination, $10 \%(3 / 30)$ of men with MG had clinical manifestations of balanoposthitis or urethral discharge, however, there were no abnormal findings in women with MG. Leucocytes were detected in $20 \%(6 / 30)$ and $40 \%(4 / 10)$ of men and women with $M G$, respectively.

The co-infections in patients with MG infected are shown in Tables 2 and 3. According to our data, $10.2 \%$ were co-infected with CT (5/49),6.1\% with NG (3/49) $2.0 \%$ with CTロNG(1/49, 8.2\% with HSV-2 (4/49), $4.1 \%$ with syphilis (4/49) and $22.4 \%$ with GW (11/49) . 
Table 2

The clinical manifestation of patients with MG who were co-infected with Chlamydia trachomatis and/or Neisseria gonococcus in an STI clinic in Guangzhou China, 2017-2018 $(n=49)$

\begin{tabular}{|c|c|c|c|c|c|c|}
\hline & & ${ }^{\mathrm{a}} \mathrm{MG}(\%)$ & $\begin{array}{l}{ }^{\mathrm{b}} \mathrm{CT} \\
\mathrm{DMG}(\%)\end{array}$ & $\begin{array}{l}\text { CNG } \\
\text { वMG(\%) }\end{array}$ & $\begin{array}{l}\text { dNGICT } \\
\text { पMG(\%) }\end{array}$ & $\begin{array}{l}\text { Total } \\
(\%)\end{array}$ \\
\hline \multicolumn{7}{|l|}{ Men $(n=36)$} \\
\hline \multirow{2}{*}{$\begin{array}{l}\text { Physical examination } \\
\text { findings }\end{array}$} & No & $27(90.0)$ & $2(6.7)$ & $1(5.3)$ & $0(0)$ & $30(83.3)$ \\
\hline & Yes & $3(50)$ & $0(0)$ & 2(33.3) & $1(16.7)$ & $6(16.7)$ \\
\hline \multirow[t]{2}{*}{ Self-reported symptoms } & No & 17(89.5) & $1(5.3)$ & $1(5.3)$ & $0(0)$ & $19(52.8)$ \\
\hline & Yes & $13(76.5)$ & $1(5.9)$ & $2(11.8)$ & $1(5.9)$ & $17(47.2)$ \\
\hline \multirow[t]{2}{*}{ Presence of leucocytes } & No & $24(100)$ & $0(0)$ & $0(0)$ & $0(0)$ & $24(66.7)$ \\
\hline & Yes & $6(50)$ & $2(16.7)$ & $3(25)$ & $1(8.3)$ & 12(33.3) \\
\hline \multicolumn{7}{|l|}{ Women $(n=13)$} \\
\hline \multirow{2}{*}{$\begin{array}{l}\text { Physical examination } \\
\text { findings }\end{array}$} & No & 10(76.9) & $3(23.1)$ & $0(0)$ & $0(0)$ & $13(100)$ \\
\hline & Yes & $0(0)$ & $0(0)$ & $0(0)$ & $0(0)$ & $0(0)$ \\
\hline \multirow[t]{2}{*}{ Self-reported symptoms } & No & $9(81.8)$ & $2(18.2)$ & $0(0)$ & $0(0)$ & $11(84.6)$ \\
\hline & Yes & $1(50)$ & $1(50)$ & $0(0)$ & $0(0)$ & $2(15.4)$ \\
\hline \multirow[t]{2}{*}{ Presence of leucocytes } & No & $6(100)$ & $0(0)$ & $0(0)$ & $0(0)$ & $6(46.2)$ \\
\hline & Yes & $4(57.1)$ & $3(42.9)$ & $0(0)$ & $0(0)$ & 7(53.8) \\
\hline
\end{tabular}


Table 3

STI infection with and without MG in STI clinic in Guangzhou China, 2017-2018 ( $n=678)$

\begin{tabular}{|c|c|c|c|}
\hline aSTI & MG negative & MG Positive & $P$ value \\
\hline b HIV & & & 0.427 \\
\hline No & $621(92.7)$ & $49(7.3)$ & \\
\hline Yes & $8(100.0)$ & $0(0.0)$ & \\
\hline${ }^{\mathrm{c}} \mathrm{CT}$ & & & 0.802 \\
\hline No & $544(92.7)$ & $43(7.3)$ & \\
\hline Yes & $85(93.4)$ & $6(6.6)$ & \\
\hline dHSV-2 & & & 0.250 \\
\hline No & $540(92.3)$ & $45(7.7)$ & \\
\hline Yes & $88(95.7)$ & $4(4.3)$ & \\
\hline e'TP $^{2}$ & & & 0.879 \\
\hline No & $606(92.8)$ & $47(7.2)$ & \\
\hline Yes & 23(92.0) & $2(8.0)$ & \\
\hline Genital warts & & & 0.271 \\
\hline No & $441(92.1)$ & $38(7.9)$ & \\
\hline Yes & 188(94.5) & $11(5.5)$ & \\
\hline${ }^{f} N G$ & & & 0.890 \\
\hline No & $574(92.7)$ & $45(7.3)$ & \\
\hline Yes & $55(93.2)$ & $4(6.8)$ & \\
\hline
\end{tabular}

Other STIs Infection Rate

Other STIs among study subjects are distributed as follows: CT, 13.4\% (91/678); NG, 8.8\% (60/678); HSV2, 13.7\% (92/678); GW, 29.4\% (199/678); and HIV, 1.2\% (8/678). Twenty-seven patients had MG and other STIs co-infection. The detailed data are shown in Table 3.

Correlates of Mycoplasma genitalium infections 
Univariate logistic regressions showed that symptomatic patients had higher $\mathrm{MG}$ infection rate $(\mathrm{P}=$ 0.004). Furthermore, patients who reported not using a condom all the time were more likely to be infected with $M G$ than patient who reported using condom all the time in the past 6 months $(P=0.043)$. Multivariable logistic regressions showed that only clinical symptom was associated with MG infection (Table 4). However, MG did not appear to be associated with other STIs according to our analysis (Table 3). 
Table 4

Regression analyses for factors associated with MG infection in Guangzhou China, 2017-2018 $(n=678)$

\begin{tabular}{|c|c|c|c|c|}
\hline & \multicolumn{4}{|l|}{ MG } \\
\hline & Univariate OR & $\begin{array}{l}P \\
\text { value }\end{array}$ & Multivariable OR & $\begin{array}{l}\mathrm{P} \\
\text { value }\end{array}$ \\
\hline \multicolumn{5}{|l|}{ Gender } \\
\hline Male & Ref & & & \\
\hline Female & $\begin{array}{l}0.929(0.482 \sim \\
1.794)\end{array}$ & 0.827 & & \\
\hline \multicolumn{5}{|l|}{ Age (ys) } \\
\hline $0-25$ & $\begin{array}{l}1.983(0.632 \sim \\
6.225)\end{array}$ & 0.241 & & \\
\hline $26-45$ & $\begin{array}{l}1.081(0.369 \sim \\
3.170)\end{array}$ & 0.887 & & \\
\hline$>45$ & Ref & & & \\
\hline \multicolumn{5}{|l|}{ Marital status } \\
\hline Single & Ref & & & \\
\hline Currently married & $\begin{array}{l}0.855(0.466 \sim \\
1.567)\end{array}$ & 0.612 & & \\
\hline Others & $\begin{array}{l}2.163(0.689 \sim \\
6.788)\end{array}$ & 0.186 & & \\
\hline \multicolumn{5}{|l|}{ Local living time } \\
\hline Less than 6 months & Ref & & & \\
\hline More than 6 months & $\begin{array}{l}1.519(0.728 \sim \\
3.171)\end{array}$ & 0.258 & & \\
\hline \multicolumn{5}{|l|}{ Education } \\
\hline Middle school or less & Ref & & & \\
\hline Senior school & $\begin{array}{l}1.806(0.572 \sim \\
5.689)\end{array}$ & 0.313 & & \\
\hline $\begin{array}{l}\text { Secondary school or junior } \\
\text { collage }\end{array}$ & $\begin{array}{l}1.560(0.542 \sim \\
4.490)\end{array}$ & 0.409 & & \\
\hline Bachelor or more & $\begin{array}{l}2.341(0.867 \sim \\
6.319)\end{array}$ & 0.093 & & \\
\hline
\end{tabular}




\begin{tabular}{|c|c|c|c|c|}
\hline & MG & & & \\
\hline Heterosexual & $\begin{array}{l}1.898(0.447 \sim \\
8.058)\end{array}$ & 0.377 & & \\
\hline MSM & Ref & & & \\
\hline \multicolumn{5}{|c|}{ Condom use in *P6m } \\
\hline Always & Ref & & & \\
\hline Not all the time & $\begin{array}{l}6.498(1.113 \sim \\
8.662)\end{array}$ & 0.035 & & \\
\hline \multicolumn{5}{|c|}{ Sexual partner in ${ }^{*} \mathrm{P} 6 \mathrm{~m}$} \\
\hline $0 \sim 1$ & Ref & & & \\
\hline $2 \sim 3$ & $\begin{array}{l}1.307(0.707 \sim \\
2.415)\end{array}$ & 0.393 & & \\
\hline$>3$ & $\begin{array}{l}1.744(0.630 \sim \\
4.826)\end{array}$ & 0.284 & & \\
\hline \multicolumn{5}{|c|}{ **Clinical symptom } \\
\hline No & Ref & & Ref & \\
\hline Yes & $\begin{array}{l}2.177(1.262 \sim \\
3.758)\end{array}$ & 0.004 & $\begin{array}{l}2.177(1.262 \sim \\
3.758)\end{array}$ & 0.004 \\
\hline
\end{tabular}

\section{Discussion}

In our population of adult men and women attending an STI clinic,the prevalence of MG was 7.2\% (7.4\% men, $6.9 \%$ women), and $38.8 \%$ of MG infected patients were symptomatic. Our study from an STI clinic in GuangDong Province adds to the sparse data of MG prevalence in China. Our prevalence rate is higher than those found in patients attending STI clinics with symptoms of urogenital tract infections or for a check up in Greece (5.7\%) [29] and Norway (4.9\%) [30], but lower than that of Denmark (9.0\%) [30], Sweden (9.8\%)[30] and US (16.7\%)[31].

In the investigation of MG in men attending an STI clinic with or without symptoms in other countries, the prevalence were still low in Norway (4.5\%)[30], similar with our result showed $8.9 \%, 9.1 \%$ and $6.4 \%$ in Denmark [30], Sweden [30] and Greece [29]. However, those were much higher in Russian (17\%) [32] and US (17.2\%) [31]. For men with urogenital symptoms, the MG positive rates were $12.8 \%(17 / 133), 12.3 \%$ and $16.7 \%$ in our study, London[33] and Brussels [34], respectively. In MSM, the prevalence of MG was $9.3 \%$ in three anatomical sites (genital/pharyngeal/rectal) in London[33] and 5.4\% in the rectal samples in San Francisco[35]. 
The MG prevalence of women in our study was $6.9 \%(95 \% \mathrm{Cl}: 3.2 \%-10.5 \%)$, which was similar with those found in women with symptoms of urogenital tract infections or for a check up in Greece (6.9\%) [29] and Norway (6.0\%)[30], but lower than that of Denmark (9.3\%) [30], Sweden (11.1\%)[30] and two researches in US $(16.3 \%, 17.5 \%)[31,36]$. Among female sex workers, the MG prevalence rate was $13.2 \%, 12.7 \%$ and 22.4\% in China[27], Kenya[37] and Honduras [38], respectively. For females at low risk of acquiring STI, the prevalence of MG was low: $1.5 \%$ in Louisiana[39] and $2.3 \%$ in London[40].

In our study, symptomatic patients were more likely to have MG infection compared to asymptomatic individuals $(12.5 \%$ Vs $5.7 \%, p=0.004)$. This was also reported in men but not in women for patients attending a young person clinic in Sweden[41]. However,some studies had the opposite conclusions, such as no statistical association between clinical symptoms and MG infection in men from an STI clinic in Guangxi Province in China[26], and no association between MG infection and microscopically defined urethritis or cervicitis in Greece[29]. These different conclusions may be related to the composition of the sample and the definition of symptoms.

In studies from Greece[29], Kenya[37] and Honduras[38], consistent condom use was not protective against MG. However, it significantly decreased the association of MG infection in our study $(p=0.043)$. Patients who reported not using a condom all the time in the past 6 months were more likely to be infected with MG than patients who reported using condom all the time in the past 6 months. Thus, consistent condom use is still highly recommended among sexually active individuals, especially in the high-risk population.

In our study, no association with other STIs was found in MG infection using the Chi-square test analysis, consistent with previous findings from UK[33, 42] and Greece[33, 42], showing that MG might be an independent pathogen in the genital tract. The high level of MG and CT/NG co-infection suggests that screening and treating CT may not have too much impact on MG since azithromycin $1 \mathrm{~g}$ which is the firstline drug in treating CT appears to be a suboptimal choice in MG treatment. In MG treatment, antimicrobial resistance (especially for macrolide resistance) has been reported[43, 44]. To avoid exacerbating more antimicrobial resistance, many resistance-guided therapy for MG infections was more effective[45]. In resource limited settings, where resistance could not be routinely tested, modifying the existing treatment guidelines and making the treatment more targeted are urgently needed.

One of the limitations of our study include the inability to recruit larger numbers of female patients and small numbers of individuals with $M G$, the other limitation is that we recruited more patients with genital warts as our clinic has a large volume of patients with genital warts, and this could have weakened the analysis of association for $M G$ infection. The results reflect the epidemiology of $M G$ in Guangdong for individuals attending an STI clinic but may not be generalized to all patient populations in China.

In conclusion, MG appears to be a relatively common infection among individuals attending an STI clinic in Guangdong(7.2\%). Symptomatic patients were statistically significantly associated with MG detection and consistent condom use was negatively associated with MG detection. MG did not appear to be 
associated with other STIs according to our analysis. Further research is needed to better understand its global epidemiology and natural history.

\section{Declarations}

\section{Ethics approval and consent to participate}

The study was approved by the Ethics Committee of Dermatology Hospital of Southern Medical University (approval no. GDDHLS - 201502, 31/03/2015). Oral informed consent was obtained from all study participants prior to inclusion in the study.

\section{Consent for publication}

Not applicable.

\section{Availability of data and materials}

The data sets during and/or analyzed during the current study available from the corresponding author on reasonable request.

\section{Competing interests}

The authors declare that they have no competing interests.

\section{Funding}

This work was supported by research fund from the Bureau of Science and Information Technology of Guangzhou Municipality (201704020219), Guangdong Provincial Medical Science and Technology (A2018346 and B2018124), the Southern Medical University (C1034403) and Research Council of Norway grant ID number 275002.

\section{Authors' contributions}

Yang LG designed the research. Zhang XH, Ke WJ, Wang LY, Chen ZY, Liao YY, Liang CM, Chen HR, Ren XQ and Yang LG completed the questionnaire and collected the clinical samples for all the patients. Zhang $\mathrm{PZ}$ analyzed and interpreted the patient data. Zhang XH was a major contributor in writing the manuscript. Ke WJ, Wang LY and Lai Sze Tso help in writing the manuscript. Huang JM performed the laboratory test for the pathogens. Yang LG, Ong JJ and Yang F reviewed the manuscript. All authors read and approved the final manuscript.

\section{Acknowledgements}

The study team would like to thank all the participants who took part in the study. 


\section{References}

1. Tully JG, Taylor-Robinson D, Cole RM, Rose DL: A newly discovered mycoplasma in the human urogenital tract. Lancet 1981, 1(8233):1288-1291.

2. Dorman CJ: Regulation of transcription by DNA supercoiling in Mycoplasma genitalium: global control in the smallest known self-replicating genome. Mol Microbiol 2011, 81(2):302-304.

3. Horner PJ, Gilroy CB, Thomas BJ, Naidoo RO, Taylor-Robinson D: Association of Mycoplasma genitalium with acute non-gonococcal urethritis. Lancet 1993, 342(8871):582-585.

4. Mo X, Zhu C, Gan J, Wang C, Wei F, Gong W, Cai Q: Prevalence and correlates of Mycoplasma genitalium infection among prostatitis patients in Shanghai, China. Sex Health 2016.

5. Horner PJ, Taylor-Robinson D: Association of Mycoplasma genitalium with balanoposthitis in men with non-gonococcal urethritis. Sex Transm Infect 2011, 87(1):38-40.

6. Horner PJ, Martin DH: Mycoplasma genitalium Infection in Men. $J$ Infect Dis 2017, 216(suppl_2):S396-S405.

7. Papes D, Pasini M, Jeroncic A, Vargovic M, Kotarski V, Markotic A, Skerk V: Detection of sexually transmitted pathogens in patients with chronic prostatitis/chronic pelvic pain: a prospective clinical study. Int J STD AIDS 2017, 28(6):613-615.

8. Ong JJ, Aung E, Read TRH, Fairley CK, Garland SM, Murray G, Chen MY, Chow EPF, Bradshaw CS: Clinical Characteristics of Anorectal Mycoplasma genitalium Infection and Microbial Cure in Men Who Have Sex With Men. Sex Transm Dis 2018, 45(8):522-526.

9. Falk L, Fredlund H, Jensen JS: Signs and symptoms of urethritis and cervicitis among women with or without Mycoplasma genitalium or Chlamydia trachomatis infection. Sex Transm Infect 2005, 81(1):73-78.

10. Bjartling $\mathrm{C}$, Osser S, Persson $\mathrm{K}$ : Mycoplasma genitalium in cervicitis and pelvic inflammatory disease among women at a gynecologic outpatient service. Am J Obstet Gynecol2012, 206(6):476 e471-478.

11. Ye H, Song T, Zeng X, Li L, Hou M, Xi M: Association between genital mycoplasmas infection and human papillomavirus infection, abnormal cervical cytopathology, and cervical cancer: a systematic review and meta-analysis. Arch Gynecol Obstet 2018, 297(6):1377-1387.

12. Ona S, Molina RL, Diouf K: Mycoplasma genitalium: An Overlooked Sexually Transmitted Pathogen in Women? Infect Dis Obstet Gynecol 2016, 2016:4513089.

13. McGowin CL, Anderson-Smits C: Mycoplasma genitalium: an emerging cause of sexually transmitted disease in women. PLoS Pathog 2011, 7(5):e1001324.

14. Napierala Mavedzenge S, Weiss HA: Association of Mycoplasma genitalium and HIV infection: a systematic review and meta-analysis. AIDS 2009, 23(5):611-620.

15. McGowin CL, Popov VL, Pyles RB: Intracellular Mycoplasma genitalium infection of human vaginal and cervical epithelial cells elicits distinct patterns of inflammatory cytokine secretion and provides a possible survival niche against macrophage-mediated killing. BMC Microbio/ 2009, 9:139. 
16. Pond MJ, Nori AV, Witney AA, Lopeman RC, Butcher PD, Sadiq ST: High prevalence of antibioticresistant Mycoplasma genitalium in nongonococcal urethritis: the need for routine testing and the inadequacy of current treatment options. Clin Infect Dis 2014, 58(5):631-637.

17. Tucker JD, Ong JJ: Mycoplasma genitalium: an important sexually transmitted infection comes into focus. Sex Transm Infect 2018, 94(4):240-241.

18. Zheng BJ, Yin YP, Han Y, Shi MQ, Jiang N, Xiang Z, Yu RX, Zhang GY, Chen XS: The prevalence of urethral and rectal Mycoplasma genitalium among men who have sex with men in China, a crosssectional study. BMC Public Health 2014, 14:195.

19. Zhao N, Li KT, Gao YY, Xu JJ, Huang DS: Mycoplasma Genitalium and Mycoplasma Hominis are prevalent and correlated with HIV risk in MSM: a cross-sectional study in Shenyang, China. BMC Infect Dis 2019, 19(1):494.

20. Chen LS, Wu JR, Wang B, Yang T, Yuan R, Zhao YY, Xu JS, Guo HX, Huan XP: Epidemiology of Mycoplasma acquisition in male HIV-1 infected patients: a multistage cross-sectional survey in Jiangsu, China. Epidemiol Infect 2015, 143(15):3327-3334.

21. Jian-Ru W, Bei W, Hao C, Jin-Shui X, Xi-Ping H: Mycoplasmas in the urine of HIV-1 infected men. Epidemiol Infect 2012, 140(6):1141-1146.

22. Wu JR, Wang B, Zhou LJ, Xie YX, Xu JS, Chen LS, Yang T, Guo HX: Mycoplasmas infection in male HIV/AIDS patients in Jiangsu, China. Microb Pathog 2013, 63:54-58.

23. Wu JR, Wang B, Chen LS, Yang T, Zhou LJ, Xie YX, Xu JS, Guo HX, Huan XP: Alarming incidence of genital mycoplasmas among HIV-1-infected MSM in Jiangsu, China. Eur J Clin Microbiol Infect Dis 2014, 33(2):189-195.

24. Yu JT, Tang WY, Lau KH, Chong LY, Lo KK, Wong CK, Wong MY: Role of Mycoplasma genitalium and Ureaplasma urealyticum in non-gonococcal urethritis in Hong Kong. Hong Kong Med J 2008, 14(2):125-129.

25. Yu JT, Tang WY, Lau KH, Chong LY, Lo KK: Asymptomatic urethral infection in male sexually transmitted disease clinic attendees. Int J STD AIDS 2008, 19(3):155-158.

26. Zheng BJ, Yin YP, Xiang Z, Han Y, Shi MQ, Jiang N, Yu RX, Chen XS: An epidemiological study of Mycoplasma genitalium infections among males attending a sexually transmitted disease clinic in Guangxi, China. Jpn J Infect Dis 2014, 67(1):17-21.

27. Yin YP, Li HM, Xiang Z, Liang GJ, Shi MQ, Zhou YJ, Han Y, Wang GQ, Wang B, Chen XS: Association of sexually transmitted infections with high-risk human papillomavirus types: a survey with $\mathbf{8 0 2}$ female sex workers in china. Sex Transm Dis 2013, 40(6):493-495.

28. Jensen JS, Bjornelius E, Dohn B, Lidbrink P: Use of TaqMan 5' nuclease real-time PCR for quantitative detection of Mycoplasma genitalium DNA in males with and without urethritis who were attendees at a sexually transmitted disease clinic. J Clin Microbiol 2004, 42(2):683-692.

29. Chra P, Papaparaskevas J, Papadogeorgaki E, Panos G, Leontsinidis M, Arsenis G, Tsakris A: Prevalence of Mycoplasma genitalium and other sexually-transmitted pathogens among high-risk individuals in Greece. Germs 2018, 8(1):12-20. 
30. Unemo M, Salado-Rasmussen K, Hansen M, Olsen AO, Falk M, Golparian D, Aasterod M, Ringlander J, Nilsson CS, Sundqvist $\mathrm{M}$ et al: Clinical and analytical evaluation of the new Aptima Mycoplasma genitalium assay, with data on $M$. genitalium prevalence and antimicrobial resistance in $M$. genitalium in Denmark, Norway and Sweden in 2016. Clin Microbiol Infect 2018, 24(5):533-539.

31. Getman D, Jiang A, O'Donnell M, Cohen S: Mycoplasma genitalium Prevalence, Coinfection, and Macrolide Antibiotic Resistance Frequency in a Multicenter Clinical Study Cohort in the United States. J Clin Microbiol 2016, 54(9):2278-2283.

32. Guschin A, Ryzhikh P, Rumyantseva T, Gomberg M, Unemo M: Treatment efficacy, treatment failures and selection of macrolide resistance in patients with high load of Mycoplasma genitalium during treatment of male urethritis with josamycin. BMC Infect Dis 2015, 15:40.

33. Huntington SE, Burns RM, Harding-Esch E, Harvey MJ, Hill-Tout R, Fuller SS, Adams EJ, Sadiq ST: Modelling-based evaluation of the costs, benefits and cost-effectiveness of multipathogen point-ofcare tests for sexually transmitted infections in symptomatic genitourinary medicine clinic attendees. BMJ Open 2018, 8(9):e020394.

34. Libois A, Hallin M, Crucitti T, Delforge M, De Wit S: Prevalence of Mycoplasma genitalium in men with urethritis in a large public hospital in Brussels, Belgium: An observational, cross-sectional study. PLoS One 2018, 13(4):e0196217.

35. Francis SC, Kent CK, Klausner JD, Rauch L, Kohn R, Hardick A, Gaydos CA: Prevalence of rectal Trichomonas vaginalis and Mycoplasma genitalium in male patients at the San Francisco STD clinic, 2005-2006. Sex Transm Dis 2008, 35(9):797-800.

36. Lillis RA, Martin DH, Nsuami MJ: Mycoplasma genitalium Infections in Women Attending a Sexually Transmitted Disease Clinic in New Orleans. Clin Infect Dis 2018.

37. Gomih-Alakija A, Ting J, Mugo N, Kwatampora J, Getman D, Chitwa M, Patel S, Gokhale M, Kimani J, Behets FS et al: Clinical characteristics associated with Mycoplasma genitalium among female sex workers in Nairobi, Kenya. J Clin Microbiol 2014, 52(10):3660-3666.

38. Johnston LG, Paz-Bailey G, Morales-Miranda S, Morgan M, Alvarez B, Hickman L, Monterroso E: High prevalence of Mycoplasma genitalium among female sex workers in Honduras: implications for the spread of HIV and other sexually transmitted infections. Int J STD AIDS 2012, 23(1):5-11.

39. Dehon PM, McGowin CL: Mycoplasma genitalium infection is associated with microscopic signs of cervical inflammation in liquid cytology specimens. J Clin Microbio/ 2014, 52(7):2398-2405.

40. Svenstrup HF, Dave SS, Carder C, Grant P, Morris-Jones S, Kidd M, Stephenson JM: A cross-sectional study of Mycoplasma genitalium infection and correlates in women undergoing population-based screening or clinic-based testing for Chlamydia infection in London. BMJ Open 2014, 4(2):e003947.

41. Nolskog P, Backhaus E, Nasic S, Enroth H: STI with Mycoplasma genitalium-more common than Chlamydia trachomatis in patients attending youth clinics in Sweden. Eur J Clin Microbiol Infect Dis 2019, 38(1):81-86.

42. Ikonomidis A, Venetis C, Georgantzis D, Giaslakiotis V, Kolovos V, Efstathiou K, Moschou M, Kappaoutsiaris E, Panopoulou M: Prevalence of Chlamydia trachomatis, Ureaplasma spp., 
Mycoplasma genitalium and Mycoplasma hominis among outpatients in central Greece: absence of tetracycline resistance gene tet(M) over a 4-year period study. New Microbes New Infect 2016, 9:8-10.

43. Romano SS, Jensen JS, Lowens MS, Morgan JL, Chambers LC, Robinson TS, Totten PA, Soge OO, Golden MR, Manhart LE: Long duration of asymptomatic Mycoplasma genitalium infection after syndromic treatment for nongonococcal urethritis. Clin Infect Dis 2018.

44. Salado-Rasmussen K, Jensen JS: Mycoplasma genitalium testing pattern and macrolide resistance: a Danish nationwide retrospective survey. Clin Infect Dis 2014, 59(1):24-30.

45. Read TRH, Fairley CK, Murray GL, Jensen JS, Danielewski J, Worthington K, Doyle M, Mokany E, Tan L, Chow EPF et al: Outcomes of Resistance-guided Sequential Treatment of Mycoplasma genitalium Infections: A Prospective Evaluation. Clin Infect Dis 2019, 68(4):554-560. 